\title{
A MATERIALIZAÇÃO DISCURSIVA DA EXCLUSÃO SOCIAL NO JORNALISMO IMPRESSO PAULISTA
}

\author{
FÁBIO FERNANDO LIMA ${ }^{1}$
}

\author{
Pontifícia Universidade Católica do Rio de Janeiro \\ Rua Marquês de São Vicente, 225 - 22451-900 - Gávea - Rio de Janeiro - RJ - Brasil \\ fabiofernandolimaduol.com.br
}

\begin{abstract}
Resumo. Circunscrito ao quadro teórico e metodológico da Análise Crítica do Discurso, o objetivo central deste trabalho é o de analisar e descrever o noticiário publicado na grande mídia impressa paulista no decorrer dos séculos XX e XXI acerca de determinados grupos marginalizados socialmente, aqui entendidos enquanto segmentos pauperizados pela precária inserção elou exclusão do mercado de trabalho, e que assim se encontram em situação de subordinação sócio-econômica, política elou cultural em relação a outro grupo, majoritário e dominante. Inscrita na tradição qualitativa e interpretativista (DENZIN; LINCOLN, 2006), os resultados desta pesquisa apontam para a existência de um preconceito de base, em consonância com a própria ideologia vigente nos grupos dominantes que controlam as grandes empresas jornalísticas, materializado mediante diversos procedimentos discursivos (muitas vezes camuflados) que buscam o estabelecimento de determinados consensos hegemônicos e a manutenção do status quo.
\end{abstract}

Palavras-chave: Análise Crítica do Discurso; noticiário; mudança discursiva; exclusão social.

\begin{abstract}
Related to the theory and methodology of Critical Discourse Analysis area (CDA), the goal of this research is to analyze and describe the newspapers published by paulista press in the course of XIX, XX and XXI ages about particular socially marginalized groups - in this research characterized as poor social segments due to low access or exclusion from the job market- and that find themselves in a socio-economic, policy and cultural subordination related to other majority and dominant group. Inscribed in the qualitative and interpretative tradition (DENZIN; LINCOLN, 2006), the results of this research point to the existence of a basic prejudice, in line with the ideology in force in the dominant groups that control the major journalistic companies, materialized through several discursive procedures (often camouflaged) that seek to establish certain hegemonic consensus and maintain the status quo.
\end{abstract}

Keywords: Critical Discourse Analysis; newspaper; discourse change; social exclusion.

\footnotetext{
${ }^{1}$ Doutor em Filologia e Língua Portuguesa pela USP. Bolsista de Pós-Doutorado Capes.
} 


\section{INTRODUÇÃO}

A abordagem da exclusão social, da intolerância, do preconceito em geral e dos estereótipos em particular, em variados tipos de discursos, nos seus mais diversos aspectos e níveis de atuação, vem se constituindo, ultimamente, em objeto de estudo tanto de linguistas quanto de pesquisadores ligados a diversas áreas de conhecimento, no Brasil e no exterior, com ampla gama de pesquisas interdisciplinares e produção teórica de qualidade a propósito do tema.

Nesse contexto, acreditamos que a adoção da abordagem crítica pode trazer um ganho teórico e metodológico importante e complementar, justamente porque, conforme apontado por numerosos autores, tais como Fairclough (2001a, 2003), Wodak (2004), dentre tantos outros, o projeto político e genealógico da Análise Crítica do Discurso (doravante ACD) concerne exatamente em desnaturalizar e tornar transparentes as relações opacas de dominação e controle, exercidas, ideologicamente, no e através do discurso.

Na verdade, a ACD apresenta-se como um campo de investigação fundamentalmente interessado em propor uma teoria e um método para descrever, interpretar e explicar as relações estruturais, transparentes ou veladas, de poder e controle manifestos na linguagem ( $c f$. WODAK, 2004). Assume-se, assim, como ponto central, a análise das maneiras pelas quais "o discurso contribui para a reprodução da desigualdade e da injustiça social, determinando quem tem acesso a estruturas discursivas e de comunicação aceitáveis e legitimadas pela sociedade" (VAN DIJK, 1994, p. 4-5).

Tomando por pressuposto o que foi explicitado nos parágrafos anteriores, faz-se importante acrescentar que há um interesse primeiro, por parte da ACD, pelo discurso veiculado pelas mídias, na medida em que estas sempre se constituíram no canal responsável pela transmissão da maior parte dos conhecimentos disponíveis e, simultaneamente, sempre se encontraram concentradas nas mãos das classes dominantes, detentoras da maioria absoluta do capital financeiro. Sob a ótica da ACD as classes dominantes exercem um controle ideológico sobre as classes dominadas, dirigindo-as da maneira como lhes convêm, a fim de manter os seus interesses e o status quo.

Conforme destaca Van Dijk (2008), o poder simbólico assumido pelos veículos de comunicação inclui a maneira de influenciar, uma vez que podem determinar a agenda da discussão pública, a proeminência de determinados tópicos em detrimento de outros e controlar quantidade e tipo de informação, especialmente no que diz respeito a quais segmentos devem ganhar espaço e de que maneira.

Se, no passado, a influência poderia ser exercida por ações pragmáticas diretivas, de acordo com Van Dijk (2008), no contexto atual, os meios de comunicação jornalísticos exercem o controle pela via persuasiva, mediante diversos mecanismos retóricos - muitas vezes camuflados - que tendem a influenciar as ações futuras dos receptores. Dessa forma, indubitavelmente, o jornalismo constitui-se em um lugar especial para a circulação e perpetração da desigualdade social e dos estigmas e estereótipos e particular, o que ressalta a importância da análise do tema em materiais advindos desse segmento. 
É partindo de um quadro assim configurado que este trabalho apresenta seu interesse central, propriamente o de analisar e descrever, sob a ótica da ACD em geral e em particular sob a perspectiva do modelo de análise tridimensional proposto por Fairclough (1995, 2001a, 2003) e suas variações, o noticiário acerca de determinados grupos excluídos em função de suas condições socioeconômicas publicado na mídia impressa do Estado de São Paulo, observando a manifestação de ideologias, aqui entendidas como resultado de práticas sociais que incidem sobre a produção discursiva, direcionadas à imposição de determinados consensos hegemônicos.

Para tal, tomamos por princípio que, ao analisarmos as práticas discursivas manifestadas no noticiário em cada um dos períodos a serem analisados - os séculos XIX, XX e XXI - e estabelecermos as devidas comparações entre eles, poderemos depreender tanto continuidades quanto mudanças nas práticas sociais subjacentes, mediante transformações na representação, ideologias e posições hegemônicas acerca dos referidos grupos. Nesse sentido, esperamos encontrar diferenças significativas entre os textos mais antigos e os contemporâneos, com uma preocupação maior, no caso dos textos atuais, em simular, mascarar a intolerância, em contraposição àqueles publicados no final do século XIX e início do XX, o que talvez se poderá atribuir às próprias transformações das práticas sociais vigentes.

Em se confirmando a hipótese de ter havido mudanças, objetivamos descrever quais tipos de transformações ocorreram ao longo destes três séculos.

\section{A OPÇÃO PELA ANÁLISE CRÍTICA DO DISCURSO}

Foi a partir dos estudos empreendidos por Norman Fairclough (1995, 2001a, 2003, dentre outros) que a ACD ganhou os contornos de um modelo teórico e analítico definido. O modelo de análise tridimensional de Fairclough (2001a, 2003), caracterizado por sintetizar as concepções de discurso com orientação, ao mesmo tempo, social e linguística, veio a ser denominado "Teoria Social do Discurso". Trata-se, em verdade, de uma abordagem caracterizada por apontar, para cada evento discursivo, três dimensões: uma constituição enquanto texto falado ou escrito; uma instância de prática discursiva, envolvendo a produção e a interpretação do texto e, por fim, o aspecto de prática social.

Ao conceber o discurso enquanto prática social, contextualizada em uma estrutura social mais ampla, materializado por textos que podem cumprir determinadas finalidades, tais como mudanças nos sistemas de conhecimentos e crenças, tanto no que se refere aos atores sociais em atividade discursiva quanto no que diz respeito ao mundo material, o autor evoca uma perspectiva funcionalista da linguagem, na medida em que postula que a língua possui funções externas ao sistema e que essas funções são as responsáveis pela organização interna do sistema linguístico. Dessa maneira, no que tange à orientação linguística de sua teoria, Fairclough faz uso da Linguística Sistêmico-Funcional (doravante LSF) de Halliday (1985).

No modelo de 2003, Fairclough apresenta um conjunto articulado de três significados: o representacional, caracterizado por enfatizar a representação de aspectos do mundo - físico, mental, social - em textos, aproximando-se da função ideacional de Halliday (1985) e, portanto, analisável a partir do sistema de transitividade; o significado acional, que focaliza o texto como modo de (inter)ação em eventos sociais, com a ação legitimando/questionando 
relações sociais e, por fim, o significado identificacional, atinente à construção e à negociação de identidades no discurso. Os significados identificacionais e acionais estão associados à metafunção interpessoal de Halliday (1985).

A análise dos significados identificacionais e acionais permitem ao analista observar as maneiras pelas quais o falante/escritor, inserido em um determinado contexto sóciocognitivo, tanto atribui determinadas identidades sociais aos atores designados em seu texto quanto expressa seus posicionamentos e julgamentos. É por meio desses significados que são instanciadas as relações pessoais e sociais dos participantes dos eventos discursivos, tanto no aspecto de sua configuração identitária como da sua relação com os outros atores sociais envolvidos no processo.

No que diz respeito aos aspectos linguísticos propriamente ditos englobados pela constituição dos significados acionais e identificacionais, faz-se importante acrescentarmos que os estudos englobados pela ACD valem-se não apenas dos aspectos gramaticais concernentes ao modo e modalidade estabelecidos por Halliday (1985) para a mencionada função, mas também das contribuições advindas de outros estudiosos que têm trabalhado de perto com a referida proposta. proposta hallidayana, os quais não apenas aplicaram essa teoria, mas também a complementaram. Para a pesquisa que aqui delineamos, levaremos em conta, sobretudo, a proposta de análise apresentada por Martin e White (2005), cujo mérito reside em sintetizar os estudos mencionados e propor uma categorização ainda mais abrangente dos mecanismos linguísticos acionados para o estabelecimento das relações interpessoais.

$\mathrm{Na}$ verdade, os autores procuram estabelecer categorias sócio-semióticas relacionadas à construção da distância, identidade, envolvimento, intimidade, e autoridade discursivas, realizadas, linguisticamente, por meio de recursos avaliativos. Trata-se das categorias de atitude, engajamento e gradação, entendidos como recursos linguísticos que atualizam posicionamentos intersubjetivos dos atores sociais em interação.

De acordo com esse ponto de vista, a atitude abrange significados graduáveis por meio dos quais o falante/escritor avalia entidades, estados de coisas e acontecimentos negativa ou positivamente. É subdividida em afeto (reações afetivas diante de uma situação ou comportamento específico), julgamento (avaliações acerca da capacidade, normalidade, tenacidade, propriedade e veracidade dos comportamentos ou atitudes humanas e/ou institucionais) e apreciação (avaliações de caráter estético acerca de elementos concretos da realidade, como objetos, ou de risco e importância, a no que tange a nominalizações processos, eventos, entidades abstratas).

A gradação, por sua vez, está relacionada ao modo pelo qual os falantes/escritores maximizam ou minimizam a força de suas asserções, tornando nítidas ou ofuscadas as categorizações semânticas com as quais operam. O engajamento, por fim, constitui-se no componente por meio do qual o autor se posiciona em relação a seu enunciado e aos enunciados potenciais de outros atores sociais envolvidos na interação. Por meio dela, objetiva-se descrever em que medida falantes/escritores avaliam as afirmações anteriores, qual o peso dessas afirmações em suas formulações e de que modo eles se engajam em relação a tais enunciados (em oposição, concordância etc.). 
No entanto, Martin e White (2005) ressaltam que, para que o produtor do texto adquira, eficientemente, o comprometimento dos leitores e ouvintes, além das categorias apontadas, este precisará contar com os argumentos dispostos e o processo persuasivo de maneira geral, embora esse aspecto não seja explorado pelos autores. Esse ponto de vista coaduna-se, aliás, com aquele assumido por Van Dijk (2008), de acordo com o qual, no contexto atual dos meios de comunicação jornalísticos, o controle é exercido pela via persuasiva, mediante diversos mecanismos retóricos que tendem a influenciar as ações futuras dos receptores. Dessa maneira, ao invés de se prescrever o que devem fazer, os jornalistas "argumentam, oferecendo justificativas econômicas, políticas, sociais e morais, e administrando o controle das informações relevantes" (VAN DIJK, 2008, p. 53).

Por isso mesmo, buscaremos estabelecer pontos de contato entre a Teoria Social do Discurso e a Nova Retórica de Perelman e Olbrechts-Tyteca (1996), objetivando descrever as maneiras pelas quais cada um desses elementos, responsáveis por acionar relações interpessoais com o leitor - a saber, as relações sociais e os sistemas de conhecimento e crença - acionam e se entrelaçam a determinadas estratégias argumentativas.

Referimo-nos anteriormente à concepção, no modelo de análise tridimensional, de uma instância enquanto prática social para cada evento discursivo, que ao lado da constituição enquanto texto falado ou escrito e prática discursiva completa o quadro de análise. $\mathrm{Na}$ verdade, a formulação, apresentada por Fairclough (2001a) da análise da dimensão da prática social "está centrada nos conceitos de ideologia e essencialmente de hegemonia, no sentido de um modo de dominação que se baseia em alianças, na incorporação de grupos subordinados e na geração de consentimento" (p. 29).

No quadro transdisciplinar da teoria crítica, podemos afirmar que a concepção de ideologia está fortemente assentada nos trabalhos acerca do assunto empreendidos por Thompson (1995). Na verdade, filiando-se às concepções críticas de ideologia, Thompson tem buscado elaborar uma acepção aplicável à análise do uso das formas simbólicas na sociedade moderna, entendendo, por formas simbólicas, "espectros de ações e falas, imagens e textos produzidos por sujeitos e reconhecidos por eles como significativos" (p. 79).

Partindo de um quadro assim configurado, Thompson (1995) apresenta uma tipologia dos modos gerais de operação da ideologia, subdivididos em cinco categorias que operam discursivamente: legitimação, dissimulação, unificação, fragmentação e reificação. Cada modus operandi possui suas próprias estratégias de construção simbólica, que a depender da forma como são construídas, podem servir para manter ou subverter, estabelecer ou minar relações de dominação.

\section{ANÁLISE DIACRÔNICA DO NOTICIÁRIO}

Tendo em vista as limitações deste artigo, procedemos à análise de duas (2) notícias publicadas na segunda metade do Século XIX, no jornal Correio Paulistano (publicado de 1854 a 1963); uma (1) notícia publicada na segunda metade do Século XX, e uma (1) notícia publicada na primeira metade do Século XXI, ambas no jornal Folha de S. Paulo (publicado de 1921 até os dias atuais). O critério para a seleção dessas notícias foi a abordagem temática - tratam de grupos excluídos socialmente. Não assumiremos, no entanto, que elas esgotem 
as possibilidades de se retratar os segmentos excluídos: antes, afirmaremos que elas expressam uma tendência de abordagem.

Conforme bem aponta Sodré (1999, p. 1), a história da imprensa no Brasil corresponde, stricto sensu, "à própria história do desenvolvimento da sociedade capitalista". Na verdade, o jornalismo impresso paulista, nascente em especial no final do século XIX, já emerge sob o controle da aristocracia de então, que passa a se expandir para o campo empresarial e político-administrativo. Tendo como pano de fundo a Revolução Industrial e a dificuldade do Governo Imperial em criar novos mercados consumidores, esses jornais adotam um posicionamento extremamente crítico em relação ao Governo Imperial.

No que diz respeito à história da pobreza no Brasil e das ações para superá-la, podemos afirmar que até 1930, ano em que é instituída a Legião Brasileira de Assistência (LBA), o trabalho social é concebido como "gesto de caridade para com o próximo" e os pobres são vistos como "grupos especiais, párias da sociedade, frágeis ou doentes, com a assistência se mesclando, dessa forma, com as necessidades de saúde", o que veio a se refletir "na própria constituição dos organismos prestadores de serviços assistenciais, que manifestaram as duas faces: a assistência à saúde e a assistência social" (SPOSATI, 2007, p. 42). Nesse primeiro momento, estabelece-se uma portanto uma associação estereotipada entre pobreza e doença, o que veio a se refletir nas posições ideológicas do jornalismo da época, sob o controle da aristocracia de então. Observe:

\section{(01) COMUNICADOS}

\section{O ECHO DA VERDADE}

Principiamos a tarefa que nos temos imposto com a analyse do um fato escandaloso quo hebdomadariamente presenciamos nesta cidade - a procissão desses infelizes a quem a morféa tem accommettido, o que, sahindo de seus escondrijos aqui vem, horrorizando a população, pedir uma esmola para matar a fome. Cumpre ao estado zelar na guarda d'aquelles que o constituem - esta vigilancia é dupla, porque olha para o moral do cidadão e para a sua saude; no primeiro caso são as leis da instrucção publica. Pobre instrucção, ãhi anda a ponta pés - mas em todo o caso sempre é bom ser chefe dessa corporação fantástica do nosso paiz, porque o grande numero do mestre-escolas das aldeas faz com quo se tenha a popularidade de um Demosthenes. Deixando porém a tal instrucção de quo tanto se falia, e de que nada se faz - diremos que o Estado vela na saúde do cidadão, estabelecendo leis hygienicas; Ah sim, leis hygienicas quo marcam quaes os títulos que deve ler o grande sacordoto da medicina — quaes os deveres que deve cumprir, mas que também entre nós são fábulas, porque qualquer Monsieur da estranja é um medico-depois que o dogma sciencia foi adoptado sem critério algum. Dizia o nosso patrício Penna na sua comedia-Noviçoque tudo se deslocava entre nós, e que as inclinações se torçião; mas ele estava bem longe do pensar que qualquer sapateiro poderia ser um dia medico - e no entanto a realidade dos factos nol-o demonstra - qualquer com uma simples tintura de historia natural é proclamado — o primeiro de uma corporação tão respeitável. /.../ ah! sim, leis hygienicas, antigamente ellas o diziam (porque hoje nos parece lettra morta) que o medico não podia ser boticário, nem o boticário medico — entretanto é o que hoje não falta /.../ Temos, dizem, um hospital para os lazaros, e entretanto ahi andam elles vagando. Qual será a causa? eis o misterio que-passamos a sondar. Lá para os districtos do bello e pitoresco bairro Paulistano, que se diz — da Luz-, bem perto das margens do formoso Tietê, encontrão-se uns casebres - que se dizem - hospital dos lázaros. /.../ Quaes leis hygienicas devem reger sobre taes estabelecimentos? /.../ a primeira cousa quo indagamos, uma resposta negativa se nos dá /.../. Não cessaremos de pedir ao governo, que lance seus olhos e cuide de cumprir um dos mais sagrados deveres que lhe está imposto-a garantia da saúde do cidadão. Não só tratar do dar incremento ao desenvolvimento intellectual do um povo animando as companhias 
dramáticas, erigindo theatros que os governos desempenham sua missão. É isso sem duvida um bom desejo que não deixamos de applaudir - mas, quando a pobresa geme, quando o enfermo grita, o governo não deve ser surdo a esses gemidos, nem insensível á essas lagrimas. /.../ Ainda, ha bem pouco tempo, se via entre nós um facto cruel o bárbaro, era a pratica do lançar nas enxovias da çadêa, de mistura com esses desalmados - o pobre e infeliz /.../. Quizeramos que o governo illustrado, que se acha ora á frente da administração, considerasse actualmente esta necessidade palpitante, visto que esta terrível enfermidadea morphéa - se acha disseminada em grande escala pela província —e que a esses infelizes coubesse melhor sorte que não a mendicidade, e a pobresa: vexando continuamente a população, que demais se horrorisa com esses hediondos espetáculos.

Convém pois, que quanto antes seja estabelecido um edifício conveniente onde se possa dar um tratamento soffrivel á esses infelizes, que, achando os meios suaves de passar os tristes restos de seus dias, resignados irão vivendo, guardados e soccorrido pela alta vigilância da autoridade. Taes são os votos que fazemos, á bem do infeliz, a quem esse terrível mal persegue, e em honra da sociedade, que não deve deixar de proteger a miséria e a enfermidade. Voltaremos a matéria se preciso fôr, com mais minuciosidade. (CP,13/07/1854)

No que se refere ao texto em tela, cumpre dizer, em primeiro lugar, que as marcas do(s) enunciador(es) claramente delineadas, aliadas à expressão de um determinado posicionamento a respeito do tema, torna-o mais semelhante aos editoriais contemporâneos que ao próprio noticiário. No entanto, no jornalismo paulista nascente do século XIX, é com esse tipo de texto, de caráter fortemente opinativo, que os jornais tratam dos assuntos inerentes ao cotidiano dos leitores.

Em (1) observamos ampla gama de recursos avaliativos; como eixo principal podemos apontar um conjunto de julgamentos negativos de sanção social. Para Martin e White (2005), os julgamentos dizem respeito às avaliações de caráter comportamental, relativas aos diversos modos de agir dos atores sociais. As avaliações de estima social relacionam-se a valores compartilhados pelos indivíduos em sua integração a diversas redes sociais e instituições, responsáveis por criar hierarquias de comportamentos práticos desejáveis e indesejáveis. Trata-se de valores ligados a comportamentos passíveis de admiração, estranhamento, menosprezo ou reconhecimento.

A sanção social, por outro lado, abarca avaliações codificadas pela cultura da escrituralidade, por meio de decretos, regras, regulamentos e leis, responsáveis pela vigilância institucional da sociedade. Nesse sentido, os valores compartilhados relacionamse às obrigações morais e éticas, à cidadania e à filiação institucional. Por essas razões, os julgamentos de sanção social implicam atitudes não de admiração ou estranhamento, mas sim, de louvor/destaque ou condenação/recriminação.

No texto em análise, observamos que o enunciador procede a diversas avaliações, apresentando, nos termos de Martin e White (op. cit.), julgamentos negativos de sansão social acerca das propriedades e qualidades do governo imperial e da categoria médica de então (cumpre ao estado zelar na guarda d'aquelles que o constituem - esta vigilancia é dupla, porque olha para o moral do cidadão e para a sua saude; no primeiro caso são as leis da instrucção publica. Pobre instrucção, ãhi anda a ponta pés-mas em todo o caso sempre é bom ser chefe dessa corporação fantástica do nosso paiz, porque o grande numero do mestre-escolas das aldeas faz com quo se tenha a popularidade de um Demosthenes; diremos que o Estado vela na saúde do cidadão, estabelecendo leis hygienicas; ah sim, leis 
hygienicas quo marcam quaes os títulos que deve ler o grande sacordoto da medicinaquaes os deveres que deve cumprir, mas que também entre nós são fábulas, dentre outras).

A essas estratégias acrescentam-se julgamentos de estima social, responsáveis por colocar em questão a capacidade da classe médica e reforçar a ideia da omissão do governo imperial (qualquer Monsieur da estranja é um medico-depois que o dogma sciencia sem privilégios - foi adoptado sem critério algum; qualquer sapateiro poderia ser um dia medico-e no entanto a realidade dos factos nol-o demonstra (...); o primeiro de uma corporação tão respeitável, dentre outras).

No plano argumentativo, as estruturas interpessoais estruturam-se por meio de um amplo discurso de justificação, cujas premissas baseiam-se em fatos. Essa trilha estabelece claramente, nos termos adotados por Perelman e Olbrechts-Tyteca (1996), um argumento pragmático, relacionado a uma ligação de sucessão, do tipo causa e efeito (sendo a ausência do estado na oferta de alternativas para coibir a mendicância e omissão na vigilância das "leis hygienicas" a causa e a proliferação da mendicância, o efeito). Atrelados a essa ideia central, observamos outros tipos de argumentos, responsáveis por sustentá-la em planos menores de generalidade: podemos apontar, por exemplo, no que tange à argumentação baseada na estrutura do real, outros vínculos do tipo causa e efeito (temos, dizem, um hospital para os lazaros, e entretanto ahi andam elles vagando. Qual será a causa? eis o misterio que passamos a sondar), o argumento de autoridade (dizia o nosso patrício Penna), o recurso à descrição do real (entanto a realidade dos factos nol-o demonstra) e, no plano dos argumentos quase-lógicos, o recurso à definição e ao conflito definicional (leis hygienicas quo marcam quaes os títulos que deve ler o grande sacordoto da medicina - quaes os deveres que deve cumprir, mas que também entre nós são fábulas, porque qualquer Monsieur da estranja é um medico - depois que o dogma sciencia sem privilégios —foi adoptado sem critério algum) e à transitividade (o medico não podia ser boticário, nem o boticário medico - entretanto é o que hoje não falta), dentre outros.

O parágrafo final do texto traz o argumento mais forte que o jornalista pretende destacar. Nesse contexto, o emprego da modalidade deôntica positiva (Convém pois, que quanto antes seja estabelecido um edifício conveniente (...)) assume contornos autoritários, tendo em vista que o alvo da proposta é o próprio governo e os seus efeitos englobam a posição não só do próprio jornal, mas também de seus leitores.

Na verdade, a voz do jornal atrela-se à voz dos leitores, membros da aristocracia da época, refletindo uma estratégia interpessoal de envolvimento. Essa estratégia é responsável por apresentar um texto engajado e disposto a representar os anseios do leitor, configurando-se como a arma de comunicação da comunidade e criando solidariedade com essa instância, de modo que os julgamentos apresentados tenham teor positivo (não cessaremos de pedir ao governo, que lance seus olhos e cuide de cumprir um dos mais sagrados deveres que lhe está imposto; quizeramos que o governo ilustrado (...)considerasse actualmente esta necessidade palpitante, (...) e que a esses infelizes coubesse melhor sorte que não a mendicidade, e a pobresa: vexando continuamente a população, que demais se horrorisa com esses hediondos espetáculos; em honra da sociedade; voltaremos a matéria se preciso fôr, com mais minuciosidade).

Chama a atenção os inúmeros recursos subjetivos que, destacados na superfície do texto, tanto reforçam o compromisso do enunciador em relação aos fatos que apresenta quanto se 
inscrevem em analogia às reações dos próprios leitores diante da mendicância. Referimonos às apreciações que se materializam em reações de impacto (escandaloso, hebdomadariamente, aplaudir, geme, grita, hediondos, bárbaro, horrorizando), de qualidade (belo) e de composição (desordem, pitoresco), que se juntam a componentes atitudinais de afeto (pobre e infeliz, infelizes, tristes).

Atrelados a alguns julgamentos de sansão social e também de estima social (illustrada, humanitária, desalmados; insensivel, cruel, malvados), essas estruturas inscrevem no texto uma visada ideológica - também aquela da classe dominante, cuja voz corresponde à voz do próprio texto - fortemente assentada em um posicionamento intolerante em relação à população de rua e a outros representantes de classes subalternas em geral (qualquer sapateiro poderia ser um dia medico; enxovias da cadêa, de mistura com esses desalmados) e bastante baseada na associação estereotipada entre pobreza e doença (esta terrível enfermidade - a morphéa - se acha disseminada em grande escala pela província - e que a esses infelizes coubesse melhor sorte que não a mendicidade e a pobresa: vexando continuamente a população, que demais se horrorisa com esses hediondos espetáculos; desses infelizes a quem a morféa tem accommettido, o que, sahindo de seus escondrijos aqui vem, horrorizando a população, pedir uma esmola para matar a fome; cumpre ao estado zelar na guarda d'aquelles que o constituem - esta vigilancia é dupla, porque olha para o moral do cidadão e para a sua saúde), dentre outros

Nos termos de Thompson (1995), observamos a legitimação da perspectiva ideológica da classe dominante, especificamente através da estratégia de universalizar os seus interesses, os quais passam a ser exibidos como se fossem os interesses de todos. A esse respeito, aliás, cumpre ressaltar que não se aponta como alternativa a inclusão desse grupo excluído - que, ademais, não tem sua perspectiva inscrita nas vozes do texto em questão - mas apenas a alternativa da plena segregação física em edifícios adequados e capazes de bani-los completamente do convívio com os demais extratos sociais, aqui apresentada para o "bem dos moradores de rua".

Em alguns pontos do noticiário publicado no Correio Paulistano, no entanto, começamos a vislumbrar a emergência de textos curtos, destinados a noticiar acontecimentos de maneira breve. Partindo sempre de uma fonte exterior claramente marcada, a coluna "Notícias e factos diversos" se apresentava por demais pequena e não era publicada cotidianamente. Diferentemente do que se observou em (1), temos em (2) um texto cuja estrutura composicional está mais associada à tradição discursiva do relatar (cf. COSTA, 2010). No entanto, em sintonia com o conjunto do noticiário publicado no jornal, mantém-se a mesma ligação com a aristocracia da época e, por conseguinte, a adoção de uma postura explicitamente intolerante face à pobreza. Observe:

(02) Santa Rita do Passa Quatro - Escreve-nos dessa localidade o nosso correspondente: Ainda continuamos a sentir faltas de criadas /.../; consta-nos, porém, que a auctoridade local vai pôr couro ao mal, reprimindo activamente a ociosidade. - Brevemente fundar-se-há nesta villa, um bem montado collegio para o sexo feminino. A direcção ficará a cargo da exma. d. Maria do Carmo Gonçalves Leito (o corpo docente compõe-se do srs. dr. AT R. Guião, o dr. Cesario do Brito Travassos, Antonio Gonçalves Leilo, d. Êlvira Guião dr. Figueiredo e d. Maria do Carmo Gonçalves Leite. Estão a cooperarem para o engrandecimento do collegio, os prestigiosos cidadãos: Jeronymo Vieira de Andrade, Antonio Bernardino Velloso, José Garcia Bocha e muitos paes de família (CP, 3/2/1855). 
Em (2), estabelece-se um contraste, materializado pelo emprego de julgamentos positivos de estima social em relação à capacidade das pessoas referidas nominalmente no texto - "os(as) senhores(as)" e "doutores(as)" (estão a cooperarem para o engrandecimento do collegio, os prestigiosos cidadãos (...)) - e o julgamento negativo de estima social empregado ao se fazer referência à tenacidade da classe trabalhadora (ociosidade), que se imiscui a outro julgamento negativo, de sansão social (pôr couro ao mal, reprimindo activamente).

Nesse sentido, o texto não só se articula em torno da subserviência à aristocracia de então, mas também coloca em tela apenas a perspectiva da classe dominante, adotada enquanto o ponto de vista do próprio jornal.

Considerando-se que o vínculo dominante de inserção na sociedade sempre foi o da integração pelo trabalho, com a transformação produtiva adquirindo preponderância nas trajetórias de exclusão social, podemos afirmar que em (2) o conjunto das estratégias acionais inscrevem, no plano identificacional, não apenas a retratação estereotipada daqueles que se encontram fora do mercado de trabalho como "vagabundos", mas também a atribuição de uma suposta "baixa qualificação" a esse segmento, passando à esfera de "despreparados", "incapacitados" - e daí de importância de "um bem montado collegio para o sexo feminino". Encontramos, aqui, as bases de uma constituição ideológica caracterizada por associar "gênero feminino" a "atividades domésticas" (feminilidade ideal) e "preguiça" à "pobreza", ou seja, a constituição estereotipada do pobre enquanto "preguiçoso", o que vem a justificar sua permanência inalterada na pirâmide social.

Dessa maneira, a posição intolerante que justifica a estrutura ideológica e os estereótipos vem sustentada pelo modo da "fragmentação". Nos termos de Thompson (1995), a fragmentação constitui-se de relações de dominação estabelecidas e mantidas no texto através da segmentação de indivíduos e grupos que possam ser uma ameaça aos grupos dominantes. Nos exemplos em tela, temos especificamente o caso do "expurgo do outro", já que as trabalhadoras "ociosas" são qualificadas como "inimigos da sociedade".

Mas é efetivamente após a Revolução de 1930 que, de acordo com Bahia (1990), a imprensa de massa começa a se delinear e a concepção de imprensa enquanto empresa tem suas origens, à medida que o país acelera a industrialização e as cidades crescem. A partir daí, a massa urbana seria, tanto informativa como publicitariamente, o mercado específico para as grandes tiragens, os grandes jornais. Como resultado, acentua-se a relação dos jornais com o poder econômico que, representado pelos mais diversos interesses, mas também identificado pelos mais sólidos anunciantes, desenvolve formas de pressão, influência e controle dos meios de comunicação. Nesse contexto, a notícia e o jornalismo como um todo vão tomando forma industrial e a matéria recomendada passa a ser uma das categorias de pressão econômica, dando "à empresa a faculdade de manipular o que vai ser impresso, no interesse dos grupos de poder" (p. 232).

Nesse contexto, em (3), faz-se importante observar que se atribui ao próprio "Exército da Salvação" o papel de qualificar sua atuação em relação ao enfrentamento da pobreza, através de diversas estruturas interpessoais de engajamento por atribuição. Mediante o emprego ora do discurso direto, ora do discurso indireto, ora do discurso indireto livre, a voz da entidade "funde-se" à do jornal, mobilizando, no plano das relações interpessoais, a incorporação ( $c f$. FAIRCLOUGH, 2001) desse discurso. Nos termos de Martin e White (2005), esses recursos funcionam como estratégias de engajamento por concordância, mediante o endosso das 
declarações.

Conforme aponta Fairclough (1995), o argumento de autoridade, muitas vezes sustentado pelo discurso relatado, assume vasta importância para o estabelecimento de determinados consensos hegemônicos. Isso porque a representação do discurso sempre pressupõe um processo ideológico cuja relevância deve ser considerada: observar vozes ausentes e presentes no texto, e suas consequências para valoração ou depreciação do que foi dito e daqueles que pronunciaram o discurso relatado, evidencia questões de poder no uso da linguagem.

$\mathrm{Na}$ verdade, o relato sempre obedece à determinada decisão do jornalista de representar o que foi dito ou escrito em determinado caminho em detrimento de outro, embora se estabeleça frequentemente uma simulação de reprodução transparente daquilo que foi dito ou escrito por outra fonte. Ademais, a mídia é mais aberta aos setores socialmente dominantes, frequentemente retomados enquanto "fontes confiáveis" e como "vozes acessadas" que emergem no discurso reportado ( $c f$. HARTLEY, 1982, p. 111 apud FAIRCLOUGH, 1995, p. 63).

No plano identificacional, observamos que a representação das ações voltadas à pobreza segue, agora, um novo viés ideológico, em sintonia com a própria história do desenvolvimento do trabalho social no Brasil: após a década de 1940, à luz da criação da Legião Brasileira de Assistência (LBA), essas ações passam a ser marcadas por traços clientelistas, assistemáticos, conservadores, com "programas sociais estruturados na lógica da concessão e da dádiva, contrapondo-se ao direito" (COUTO, 2006, p. 71). Ao se tornarem beneficiários dessas ações, cobertas pelas obras de caridade, reforça-se o processo de exclusão, à medida que tais ações passam a ser entendidas enquanto "favor" prestado pelas classes dominantes às classes subalternas:

\section{Exército da Salvação angaria fundos com "Panelas de Natal"}

"Salvo para Servir" é o lema do Exército da Salvação e com base nele aquela entidade religiosa-assistencial vem, a exemplo dos anos anteriores, colocar em vários locais do centro da cidade as tradicionais "Panelas de Natal" com o objetivo de angariar fundos para ajudar a necessitados.

O Exército da Salvação, que está comemorando este ano o seu centenário, pretende angariar neste natal aproximadamente $\mathrm{Cr} \$ 6$ milhões em donativos que serão aplicados em benefício do Leprosário Pirapitingui, situado próximo a Sorocaba, e do Santuário dos Tuberculosos de São José dos Campos.

Parte dos donativos arrecadados será doado às famílias pobres da capital, que receberão vales de cinco mil cruzeiros para trocar por mercadorias em determinados estabelecimentos comerciais da cidade. Para essa distribuição, há um selecionamento prévio das famílias realmente necessitadas.

\section{FINALIDADES}

O Exército da Salvação foi fundado em 1865, quando William Booth declarou guerra à pobreza, vício e pecado num dos bairros mais miseráveis do leste de Londres. /.../ No Brasil, o Exército da Salvação trabalha desde o ano de 1922. /.../ A organização é alicerçada em bases doutrinárias do Protestantismo e sua inspiração vem dos cultos, em seus templos, ou mesmo das pregações em praças públicas, dos Evangelhos e da tese de salvação para todos os homens.

O Exército, que procura colocar em prática a ação cristã, antes de tudo, promove também visitas a pessoas pobres, a hospitais e prisões. A fim de atingir diretamente as massas 
indiferentes à religião, o Exército realiza reuniões nas ruas e praças, utilizando bandas, cânticos e instrumentos musicais.

Sua ação se baseia nos três preceitos de seu fundador: "Ide aos pecadores e aos pobres, levando-lhes sopa do alimento do corpo, sabão para a reabilitação social e Salvação (a reabilitação social através de Cristo)". (FSP, 9/12/1965, p. 11)

Com a implantação definitiva da sociedade do espetáculo - vigente nos últimos quarenta anos, acompanhando as características das sociedades pós-moderna - os veículos de comunicação assumem, definitivamente, papel central. Desde então, passam a se definir como organismos especializados em responder a uma demanda social por justiça e cidadania, e os jornais começam a adotar, como premissas para suas linhas editoriais, um jornalismo pretensamente "crítico", "apartidário" e "pluralista". Como resultado, a estrutura composicional do gênero "notícia" sofre mudanças profundas, assentadas na tentativa de construção da objetividade.

O conceito de "espetáculo" se refere tanto à experiência prática da primazia dos desígnios da "razão mercantil" sobre os demais aspectos da vida social quanto "às novas técnicas de governo usadas para avançar "o empobrecimento e a sujeição", "conquistando o controle social por intermédio mais do consenso que da força" (FREIRE FILHO, 2003, p. 37). Como resultado, a persuasão também assume papel central. Observe:

\section{(04) Bolsas para baixa renda extrapolaram o Orçamento}

Pilares da ação do Estado no país, os programas de transferência direta de renda às famílias contribuíram para a queda da pobreza e da desigualdade nos últimos anos, mas deixaram de caber no Orçamento federal.

Só nos anos de administração petista, benefícios previdenciários, trabalhistas e assistenciais saltaram do equivalente a 7,3\% da renda nacional, em 2003, para 9,4\% no ano passado.

Em valores de hoje, é como se a despesa anual do governo com essa finalidade tivesse crescido em cerca de R $\$ 120$ bilhões, sem um aumento correspondente da arrecadação tributária.

Com a recessão econômica, a receita total da União caiu de $18,9 \%$ do PIB, recorde atingido em 2011, para 17,6\% no ano passado -quase os mesmos 17,4\% de 2003 .

Previdência Social, assistência a idosos e deficientes, seguro-desemprego, abono salarial e Bolsa Família respondem hoje por metade do gasto federal, excluindo da conta os encargos da dívida pública. E esse gasto deverá superar a receita deste ano em algo como R\$ 100 bilhões.

A escalada das despesas com esses programas começou com a Constituição de 1988, que fixou novos direitos; tornou-se mais visível quando o Plano Real, de 1994, derrubou a hiperinflação; ganhou impulso a partir da década passada com a formalização do emprego e o envelhecimento da população.

\section{DESIGUALDADE}

Do ponto de vista da distribuição e da melhora na renda, os programas sociais e a Previdência tiveram maior impacto entre os mais pobres. Mas, de modo geral, vieram do trabalho e da empregabilidade ao longo dos 13 anos do PT na Presidência as maiores contribuições para a queda na desigualdade.

No período, segundo dados do Centro de Políticas Sociais da FGV, todos os estratos da população tiveram melhora na renda acima dos índices de inflação: a dos 10\% mais pobres aumentou $129 \%$; a dos $10 \%$ mais ricos, $32 \%$.

Quanto mais pobre, maior o impacto dos programas sociais e da Previdência. Mas, na média, foi a renda do trabalho que teve maior peso, de $78 \%$ para a melhora dos rendimentos. Previdência teve participação de 19\%, e o Bolsa Família, de 3\%. 
No decil mais pobre, o peso do Bolsa Família sobe a 31\%, a Previdência cai para $10 \%$, e a renda do trabalho, para 59\% (e é preponderante mesmo assim).

\section{ADVERSÁRIOS}

A atual recessão e o alto nível de desemprego (10,9\% da força de trabalho) são hoje, portanto, os maiores adversários da melhora na distribuição de renda. Não por acaso, o último trimestre de 2015 foi o primeiro período desde 1999 (início da série) em que renda e desigualdade tiveram uma piora juntas no país. (FSP, 15/05/2016)

Cumpre observar que os recursos avaliativos, bem como o processo persuasivo de forma geral, emergem de modo bastante camuflado, em contraposição aos textos anteriores. Em (4) observamos um texto construído basicamente sob tratamento "factual" dos temas em questão, como se os "fatos falassem por si mesmo". Não por acaso, os recursos argumentativos utilizados fundam-se praticamente em argumentos baseados na estruturação do real, sobretudo por meio dos vínculos de sucessão, do tipo causa e efeito (no caso da grande relação central estabelecida, temos os programas de transferência direta de renda às famílias de baixa renda elaborados ao longo dos anos enquanto a causa de um efeito percebido nos dias de hoje, o rombo no orçamento).

Essas relações de sucessão vêm sustentadas por uma ampla gama de argumentos, como o argumento quase lógico da comparação (em valores de hoje, é como se a despesa anual do governo com essa finalidade tivesse crescido em cerca de $R \$ 120$ bilhões, sem um aumento correspondente da arrecadação tributária) e, sobretudo, o argumento de autoridade, balizado sob a forma de um conjunto de dados estatísticos que resultaram de pesquisas acerca do assunto, como os "dados do Centro de Políticas Sociais da FGV" e outros dados que não têm a fonte explicitada no texto.

Nesse sentido, é importante observar que se atribui a essas fontes confiáveis - no caso, a voz dos institutos de pesquisas econômicas - sustentar a argumentação em curso, mediante diversas estruturas interpessoais de engajamento por atribuição. De forma análoga ao que observamos em (4), esses recursos funcionam como estratégias de engajamento por concordância, mediante o endosso dos dados apresentados.

A supressão de vozes dissonantes que contestam esse tipo avaliação econômica universaliza uma perspectiva particular e ajuda a constituir um determinado consenso hegemônico negativo acerca dos programas de transferência de renda, mediante a estratégia da "dissimulação" ( $c f$. THOMPSON, op. cit.) da estrutura ideológica de dominação em curso, sustentada, neste caso, por uma "subjetividade antipública que segrega e elabora, por meio da comunicação midiática, uma ideologia antiestatal, fundada na ideia da dilapidação financeira do estado e na imagem do estado devedor" (OLIVEIRA, 1997, p. 32). Nesse sentido, os direitos sociais e trabalhistas, consolidados a partir da promulgação da Constituição de 1988, período em que assistência social deixa para trás seu caráter subsidiário e passa a ser entendida enquanto direito, integrando um tripé da seguridade social - juntamente com os direitos à saúde e à previdência social são transformados em obstáculos ao desenvolvimento econômico do país: a proteção social se transforma em "custo Brasil” (p. 32). 


\section{CONCLUSÃO}

Mediante a breve comparação entre textos publicados no final do século XIX, ao longo do século XX e início do XXI, fica destacada, no caso dos textos em análise, a existência de um posicionamento ideológico fortemente vinculado às classes dominantes perpassando a elaboração do noticiário dos grandes jornais paulistas acerca da pobreza e das ações necessárias para superá-la. Essa constatação ecoa a posição, sustentada pela $\mathrm{ACD}$, de acordo com a qual os veículos de comunicação se apresentam como mecanismos de controle ideológico das classes dominantes sobre as classes dominadas, "desempenhando um papel essencial ao dar sustentação ao aparato ideológico que permite o exercício e a manutenção do poder” (VAN DIJK, 2008, p. 46).

No que se refere à análise da evolução diacrônica do próprio gênero notícia, podemos afirmar que a são os breves relatos, correspondentes à tradição discursiva do relatar (cf. COSTA, 2010) - caracterizados pela apresentação de sequências descritivas e marcados, muitas vezes, pelo argumento de autoridade - bastante raros no final do século XIX - que se impõe diacronicamente. Essa mudança vem determinada, sobretudo, por matizes ideológicos que, em sua essência, vão operando gradativamente a transformação para um noticiário escrito sob o prisma de um jornalismo pretensamente "objetivo".

Essa tentativa de construção da objetividade materializa-se através de diversas estratégias camufladas de persuasão e controle, as quais puderam ser verificadas com a breve análise dos recursos avaliativos e dos tipos de argumentos empregados. Se nos exemplares do final do século XIX e do início da segunda metade do século XX constatamos todo tipo de argumentos, aliados a uma série de avaliações, a análise do texto do início do século XXI ratifica não apenas a posição de Van Dijk (2008) de acordo com a qual, nas sociedades modernas, o poder exercido pelos jornais inclui maneiras mais sutis de influenciar, mas também corrobora a tese da incidência da mudança social - ou das determinações sócio-histórico-ideológicas - sobre as mudanças discursivas, inclusive no que diz respeito aos aspectos concernentes à própria estrutura composicional dos gêneros discursivos ao longo dos tempos.

\section{REFERÊNCIAS}

BAHIA, Juarez. Jornal, história e técnica. 4a. ed. São Paulo: Ática, 1990.

COSTA, Alessandra. Tradições Discursivas em jornais paulistas de 1854 a 1901: gêneros entre a história da língua e a história dos textos. Munich: Grin, 2010.

COUTO, Berenice. O Direito Social e a Assistência Social na Sociedade Brasileira: uma equação possível? São Paulo: Cortez, 2006.

DENZIN, Norman; LINCOLN, Yvonna (Orgs.). O planejamento da pesquisa qualitativa: teorias e abordagens. Porto Alegre: Artmed Bookman, 2006.

FAIRCLOUGH, N. Analysing Discourse: textual analysis for social research. London: Routledge, 2003.

FAIRCLOUGH, N. Discurso e mudança social. Brasília: Editora da Universidade de Brasília, 2001a.

FAIRCLOUGH, N. Critical discourse analysis as a method in social scientific research. In: WODAK, Ruth; MEYER, Michael (Orgs.) Methods of critical discourse analysis. London, Thousand Oaks, Nova Delhi: Sage, 2001b. pp. 121-138. 
FAIRCLOUGH, N. Critical Discourse Analysis: the critical study of language. London; New York: Longman, 1995.

FREIRE FILHO, João. A sociedade do espetáculo revisitada. FAMECOS, Porto Alegre, $\mathrm{n}^{\circ}$ 22, p. 33-46, 2003.

HALLIDAY, M. An Introduction to functional grammar. London: Edward Arnold, 1985.

MARTIN, James; WHITE, Peter. The language of evaluation: appraisal in English. New York/Hampshire: Palgrave Macmillan, 2005.

OLIVEIRA, Francisco. Vanguarda do atraso e atraso da vanguarda: Globalização e neoliberalismo na América Latina. Praga, São Paulo, n. 4, p. 31-33, 1997.

PERELMAN, Chaim; OLBRECHTS-TYTECA, Lucie. O tratado da argumentação: a nova retórica. São Paulo: Martins Fontes, 1996.

SODRÉ, Nelson. História da imprensa no Brasil. Rio de Janeiro: Mauad, 1999.

SPOSATI, Aldaíza. A menina LOAS: um processo de construção da assistência social. São Paulo: Cortez, 2007.

THOMPSON, J. Mídia e modernidade: uma teoria social da mídia. Petrópolis: Vozes, 2008. THOMPSON, J. Ideologia e cultura moderna: teoria social crítica na era dos meios de comunicação de massa. Petrópolis: Vozes, 1995.

VAN DIJK, Teun. Discurso e poder. São Paulo: Contexto, 2008.

VAN DIJK, Teun. Discurso, poder y cognición social. Cuadernos, Maestría en Lingüística. Escuela de Ciencia del Lenguaje y Literaturas, Cali, Año 2, 1994. Disponível em www.discursos.org/Art/Discurso, \%20poder\%20y\%20cognici\%F3n\%20social.pdf. Acesso em 6 de junho de 2018.

WODAK, Ruth. Do que trata a ACD: um resumo de sua história, conceitos importantes e seus desenvolvimentos. Linguagem em (Dis)Curso, Tubarão, v. 4, n. especial, p. 223-243, 2004.

Artigo recebido em: fev. de 2019.

Aprovado e revisado em: ago. de 2019.

Publicado em: dezembro de 2019.

Para citar este texto:

LIMA, Fábio Fernando. A materialização discursiva da exclusão social no jornalismo impresso paulista. Entremeios [Revista de Estudos do Discurso, ISSN 2179-3514, on-line, www.entremeios.inf.br], Seção Estudos, Programa de Pós-Graduação em Ciências da Linguagem (PPGCL), Universidade do Vale do Sapucaí (UNIVÁS), Pouso Alegre (MG), vol. 19, p. 129-143, jul. - dez. 2019.

DOI: http://dx.doi.org/10.20337/ISSN2179-3514revistaENTREMEIOSvol19pagina129a143 